\title{
OVERMUNDO: UM CASO DE AUTORIA PEER-TO-PEER
}

\section{Beatriz Cintra Martins}

Doutora em Ciências da Comunicação.

Pesquisadora dos grupos de pesquisa Economias Colaborativas e Produção P2P no Brasil (IBICT/ UFRJ) e Novas Tecnologias, Cultura e Práticas Interativas e Inovação em Saúde (FIOCRUZ).

\begin{abstract}
Resumo
O deslocamento do paradigma autoral na atualidade, mais aberto e interativo, está relacionado à emergência da economia peer-to-peer. Casos emblemáticos deste modelo produtivo, como o sistema operacional Linux e a enciclopédia colaborativa Wikipédia, são também exemplos notórios de experimentação de um novo modelo autoral baseado em interações distribuídas em rede. Neste artigo, num primeiro momento, é feita uma reflexão sobre a concepção de autoria, tendo como base o pensamento de Michel Foucault. Em seguida, exploramos algumas características do processo autoral P2P que tem lugar nas redes de comunicação. Por último, apresentamos o caso do website Overmundo como um exemplo brasileiro de produção peer-to-peer.
\end{abstract}

Palavras-chave

Autoria. Produção. Peer-to-Peer. Overmundo.

\begin{abstract}
Currently, the shifting of the authorship paradigma, to a more open and interactive one, is related to the emergence of the peer-to-peer economy. Emblematic cases of this productive model, such as the Linux operating system and the collaborative encyclopedia Wikipedia, are also remarkable examples of experimentation of a new authorship model, based on interactions distributed through networks. In this article, we began by reflecting on the authorship concept, based on Michel Foucault's thinking. We then explore some characteristics of the peerto-peer authorship process that takes place in communication networks. Finally, we present the case of the Overmundo website, as an example of the Brazilian peer-to-peer production.
\end{abstract}

Keywords

Authorship. Peer-to-Peer. Production. Overmundo.

\section{INTRODUÇÃO}

Um dos aspectos que merece ser analisado no contexto da economia peer-to-peer, baseada em modelos produtivos horizontais e colaborativos, diz respeito à questão autoral. Antes entendida como algo de natureza individual e privada, a noção de autoria sofre um deslocamento sob o impacto das redes de comunicação e passa a ser mais interativa e aberta. Emblemáticos exemplos da produção P2P, como o sistema operacional Linux, desenvolvido por milhares de programadores espalhados por diversos continentes, e a enciclopédia

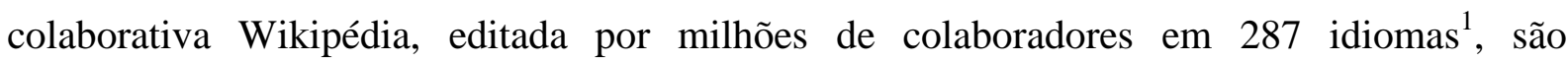
expressões desse novo paradigma autoral que se dá de forma distribuída através de interações em rede.

\footnotetext{
${ }^{1}$ Dados relativos a abril de 2014 .
} 
Essa mudança problematiza a concepção tradicional de autoria em várias direções. Por um lado, a produção não é mais referida necessariamente a um indivíduo em particular, mas potencialmente a uma multidão. A figura do autor, portanto, como alguém que detém um tipo de talento ou conhecimento, um artista ou um especialista, é substituída por uma atuação distribuída em rede, que combina diversas competências e níveis de contribuição. Nesse contexto, é cada vez mais comum a produção compartilhada de obras das mais diversas naturezas - softwares, obras artísticas, publicações - nas quais a atribuição de autoria se apresenta de forma difusa.

Por outro lado, a obra deixa de ter contornos definidos, e torna-se um processo potencialmente sempre inacabado, passível de novas interações e novos impulsos que poderão levá-la a caminhos inimaginados no momento primeiro de sua criação. Seja na forma de novas edições em uma plataforma wiki, seja na forma de novas linhas de comando num software, uma produção em rede pode receber acréscimos ad infinitum, o que impacta de forma significativa a própria noção que se tem de obra como algo acabado. Nesse contexto, a obra está em aberto e pode se atualizar, inclusive se transformar significativamente, a partir de novas intervenções não necessariamente esperadas ou planejadas.

Um ponto que tem tido muita relevância na atualidade é o que diz respeito à propriedade intelectual. Como gerir um bem criado por uma multidão? Que direitos devem ser garantidos, a quem e a que propósito? Este é um aspecto que tem sido tratado com muita atenção pelos envolvidos na produção peer-to-peer no sentido de assegurar que o trabalho coletivo se constitua em um bem comum para o usufruto de uma comunidade ou da sociedade como um todo, e não corra o risco de ser apropriado de forma privada.

Neste artigo, iremos abordar essas questões através da análise do website Overmundo ${ }^{2}$, dedicado à cultura brasileira e editado pelo próprio público. Num primeiro momento, faremos uma reflexão sobre o estatuto da autoria e sua configuração na atualidade. Em seguida, apresentaremos o modelo de publicação do website, como um caso de produção P2P brasileira.

\section{A AUTORIA EM QUESTÃo}

Para discutir a questão da autoria, partimos de algumas reflexões de Michel Foucault sobre o tema. Em sua célebre palestra, “O que é um autor?”, proferida na Société Française de Philosophie, em 1969, o filósofo francês explora a questão autoral entendendo o autor não

\footnotetext{
${ }^{2}$ Endereço eletrônico em: 〈http://www.overmundo.com.br〉.
} 
como um indivíduo, mas como aquilo que faz o discurso convergir, que lhe dá unidade e coerência. Para isso, propõe o conceito de função autor: "A função autor é, assim, característica do modo de existência, de circulação e de funcionamento de alguns discursos no interior de uma sociedade" (FOUCAULT, 2006, p. 46).

Em sua argumentação, Foucault ressalta a diversidade de modelos autorais em diferentes épocas e contextos culturais, chamando a atenção para a historicidade da autoria:

Houve um tempo em que textos que hoje chamaríamos "literários" (narrativas, contos, epopéias, tragédias, comédias) eram recebidos, postos em circulação e valorizados sem que se pusesse a questão da autoria; o seu anonimato não levantava dificuldades, a sua antiguidade, verdadeira ou suposta, era uma garantia suficiente. (FOUCAULT, 2006, p. 48).

No entanto, alerta, a partir dos séculos XVII e XVIII há uma mudança, pois os discursos literários passam a precisar da chancela de um autor para serem recebidos, assim como de referências a respeito das circunstâncias e dos propósitos de sua criação. De fato, ao percorrer história da autoria, constatamos que não só a questão da atribuição variou em diferentes períodos históricos, mas também outras características. Na Antiguidade e no período medieval, por exemplo, os processos autorais tinham uma configuração mais coletiva e aberta. Foi durante a Modernidade que se desenvolveu a noção de autoria como algo de natureza individual e proprietária, o que se intensificou ainda mais com o movimento do Romantismo, quando ganhou relevância a figura do gênio criador. A concepção de autoria, portanto, não é universal ${ }^{3}$.

Outro ponto a ser ressaltado é que, para Foucault, a autoria não está de modo algum ligada a um sujeito em especial. É uma função organizadora da circulação do discurso em dada sociedade, que pode eventualmente adquirir contornos individuais, mas, para ele, o que existe no máximo são posições de discursividade. Quem fala é sempre uma variável que acede a um discurso que está para além dele, na cultura. Em suas palavras: “[a função autor] não reenvia pura e simplesmente para um indivíduo real, podendo dar lugar a vários "eus" em simultâneo, a várias posições-sujeitos que classes diferentes de indivíduos podem ocupar”. (FOUCAULT, 2006, p. 55).

A ideia da autoria como uma função para além de um sujeito particular, também está colocada quando o filósofo pensa o autor como um princípio de rarefação do discurso, que faz

\footnotetext{
${ }^{3}$ As variações dos modelos autorais em diferentes épocas foram analisadas anteriormente no artigo MARTINS, Beatriz Cintra. Autoria, propriedade e compartilhamento de bens imateriais no capitalismo cognitivo. Liinc em Revista v. 7, n. 2, 2011, p. 358-374.
} 
parte de um conjunto de procedimentos que tem por objetivo organizar e controlar a circulação do discurso na sociedade:

Creio que existe outro princípio de rarefação de um discurso [...]. Trata-se do autor. $\mathrm{O}$ autor, não entendido, é claro, como o indivíduo que pronunciou ou escreveu um texto, mas o autor como princípio de agrupamento do discurso, como unidade e origem de suas significações, como foco de sua coerência (FOUCAULT, 2001, p. 26).

Acompanhando o seu pensamento, podemos considerar que a função autor se apresentou de forma diversa em diferentes épocas, mas em cada uma delas fez parte de um mecanismo social de regulação da discursividade. Nesse sentido, podemos entender a autoria peer-to-peer como uma nova configuração da função autor, de caráter mais interativo e distribuído, que emerge na atualidade sob o impacto das redes de comunicação.

Analisaremos a seguir, em diálogo com outros autores, algumas das características desse novo paradigma autoral. Embora esses pesquisadores não se refiram especificamente ao conceito de peer-to-peer, as questões por eles levantadas dizem respeito às produções colaborativas em rede e por isso entendemos sua pertinência para nossa reflexão.

\section{Anonimato e nomeação}

Um primeiro ponto que merece ser analisado com mais cuidado é relativo ao anonimato. Serelle (2006), ao pensar a autoria no ambiente digital, faz referência a Foucault, especificamente à condição hipotética imaginada pelo filósofo na qual os discursos pudessem circular sem atribuição, em um total desaparecimento da figura do autor, no anonimato do murmúrio (FOUCAULT, 2006). Para Serelle, a rede atualizaria essa imagem na medida em que a criação textual através das redes digitais colocou em crise a figura do autor, como uma entidade cêntrica que ordena os discursos na sociedade, dando lugar a um processo polifônico, múltiplo e descentralizado, marcado pela anonimidade:

Sua lógica [do ciberespaço] é a da substituição do sujeito individual pelo sujeito coletivo ou transindividual, participante de uma obra desencadernada, hipertextual e sem contornos, que se propaga, usualmente, na anonimidade. (SERELLE, 2006, p. 73).

Não há dúvida de que a produção discursiva como algo próprio de um sujeito individual está sendo desestabilizada nesse meio, e que é mais acertado pensar em um sujeito coletivo ou transindividual como seu autor. No entanto, a afirmação de que se trata de uma atuação anônima é já bastante questionável. Não podemos ignorar que há na nossa cultura, 
como bem sinalizou Weissberg (2003), uma importância crescente da assinatura, isto é, da busca por crédito e por identificação.

Os projetos interativos no ciberespaço não prescindem da nomeação da contribuição de cada participante. Para entender essa dinâmica, vale lembrar que vários pesquisadores têm pensado a economia da rede como uma economia da dádiva, que pressupõe outro tipo de moeda de troca, calcada por sua vez na reputação e na meritocracia ${ }^{4}$. Nesse contexto, cada um que contribui com a criação de uma obra quer deixar registrada a sua contribuição, a fim de que ela possa somar pontos à sua reputação junto àquele grupo ou comunidade. O exemplo do desenvolvimento de software livre, como o já citado Linux, mostra isso com clareza: a cada nova versão de um programa, mesmo que seja uma pequena modificação, todos os que contribuíram para o seu desenvolvimento devem ter seu crédito explicitamente registrado. E trata-se de uma produção aberta e coletiva, feita de forma distribuída e auto-organizada em rede, típica da cibercultura.

$\mathrm{Na}$ produção textual, temos o exemplo da Wikipédia onde, se há uma expressiva participação anônima não contabilizada, não menos significativa é a contribuição de milhões de colaboradores registrados que fazem questão deixar sua assinatura em cada acréscimo feito, o que fica anotado na subpágina histórico de cada verbete. Com isso, ganham renome junto à comunidade e podem ascender na estrutura do sistema editorial da enciclopédia ${ }^{5}$.

$\mathrm{O}$ anonimato nas produções textuais em rede parece ser um recurso para aqueles que por algum motivo não querem se identificar, sejam eles de ordem política, profissional ${ }^{6}$, ou o chamado $\operatorname{troll}^{7}$, mas está muito longe de representar a natureza dessa produção. Neste ponto, é interessante levar em conta a observação de Weissberg:

A época atual verá reforçar-se a pertinência do autor individual (forjado pela cultura do livro) mergulhando ao mesmo tempo em uma configuração tecnocultural que articula o indiviso e o indivíduo. Assim, há de se desenhar precisamente a figura do autor em coletivo, totalmente voltada para o prazer do coletivo [...] e levada incessantemente a produzir diferença, a produzir original; esse endereçamento à originalidade torna-se, é claro, uma condição coletiva. (WEISSBERG, 2003, p. 124).

\footnotetext{
${ }^{4}$ Sobre a importância da reputação e da meritocracia na cultura da rede, conferir CASTELLS, Manuel. A galáxia da Internet: Reflexões sobre a Internet, os negócios e a sociedade. Tradução Maria Luiza X. de A. Borges. Rio de Janeiro: Zahar, 2003; e RHEINGOLD, Howard. Smart mobs: the next social revolution. Cambridge: Perseu, 2003.

${ }^{5}$ Para mais detalhes sobre o sistema editorial da Wikipédia, conferir BUTLER, Brian; JOYCE, Elisabeth; PIKE, Jacqueline. Don't look now, but we've created a bureaucracy: the nature and roles of policies and rules in Wikipedia. In: Annual SIGCHI Conference on Human Factors in Computing Systems, 26, 2008, Florence, Italy. Proceedings... New York: Association for Computing Machinery, 2008, p. 1101-1110.

${ }^{6}$ Os administradores do website Slashdot <http://slashdot.org〉, por exemplo, argumentam que aceitam as contribuições de anônimos porque muitas vezes as pessoas querem participar das discussões, mas não querem se expor por temer represálias a suas carreiras.

7 Pela definição da Wikipédia: "Um Troll, na gíria da internet, designa uma pessoa cujo comportamento tende sistematicamente a desestabilizar uma discussão, provocar e enfurecer as pessoas envolvidas nelas".
} 
Sendo assim, podemos então considerar que o processo autoral peer-to-peer combina o coletivo, a obra aberta e inacabada, com um traço também individual, herdado da cultura do livro e adequado à economia da dádiva, formando uma nova configuração que não corresponde nem à dissolução completa do autor, mas também não à autoria individualizada. Esse "autor em coletivo", como propõe Weissberg, é descentrado, distribuído, autoorganizado, interconectado, interativo, dialógico, entre outros atributos. Porém, mantém ainda uma ligação com algo de natureza individual: o indivíduo contribui para a construção de um coletivo comum, mas quer que seu acréscimo, sua diferença, seja devidamente registrado e creditado.

\section{A rede e a rarefação do discurso}

Outro aspecto que vale abordar é o da capacidade da comunicação em rede em promover uma grande alteração naquilo que Foucault chama de princípio de rarefação do discurso, uma das qualidades da função autor, que mencionamos anteriormente, como organizadora da circulação do discurso na sociedade. Ao refletir sobre as primeiras experiências de arte telemática ${ }^{8}$, Ascott (1984) argumenta que a dinâmica autoral em rede criaria uma nova ordem do texto e, consequentemente, uma nova ordem do discurso. Essa novidade, para ele, estaria para além do que foi pensado por Foucault, na medida em que supõe um texto tecido de forma compartilhada, numa autoria distribuída e negociada, que escaparia do controle e da delimitação do discurso.

É preciso ter cuidado para não tirar conclusões apressadas. Pois, certamente, o que Foucault chama de ordem do discurso é algo que não se reduz a uma mera interdição do discurso, mas diz respeito a sua organização e circulação social, em uma lógica muito mais complexa. Sendo assim, nos parece que é possível pensar, sim, em uma distensão ou um afrouxamento da rarefação do discurso com a circulação muito mais polifônica de falas vindas de todos os extratos sociais e, em termos globais, potencialmente de todas as identidades culturais e posições político-ideológicas existentes na atualidade.

O que se constata é que esses discursos polifônicos e díspares estão na verdade em disputa na rede. Um bom exemplo é o caso dos artigos da Wikipédia, onde diferentes pontos de vista negociam o conteúdo final. Na maioria das vezes essa negociação é possível, em

\footnotetext{
${ }^{8}$ Roy Ascott foi o idealizador da obra La Plissure du Text, um experimento pioneiro de narrativa, escrita de forma distribuída através de redes telemáticas por artistas e grupos de artistas, realizada em dezembro 1983, como parte do Electra, Electricity and Electronics in the Art of the XXth Century, no Musée d'Art Moderne de la Ville de Paris.
} 
outros pontos mais polêmicos, a discussão se torna interminável, o que levou os administradores da enciclopédia a centralizarem a edição de vários verbetes desse tipo, através da criação de páginas protegidas ${ }^{9}$.

Outro ponto que vale ser observado é que esses discursos são, em grande parte, produzidos através de redes sociais cognitivas ${ }^{10}$. Um exemplo disso são as publicações interativas, como o Overmundo ou o Slashdot, nas quais o conteúdo é construído de forma coletiva. No primeiro, as matérias são postadas pelo próprio público, que depois pode também comentá-las. Já o segundo funciona como um fórum de discussão no qual centenas de pessoas comentam uma notícia. Nesses ambientes, as interações entre os participantes, através de comentários, é que definem o conteúdo que prevalecerá. Sendo assim, podemos dizer que a rarefação do discurso proporcionado pelo autor em rede segue outros parâmetros, que não são mais tão restritivos como na era do livro impresso ou da mídia de massa, mas se dão em um processo de negociação, aberto e inacabado, e são validados através de redes cognitivas.

No entanto, é preciso reconhecer que novas ordens na circulação do discurso são estabelecidas mesmo nos ambientes descentralizados e auto-organizados. O estudo de caso sobre Slashdot, dedicado especialmente à comunidade hacker, revelou que as opiniões ideologicamente contrárias ao software de código aberto tendiam a ser marginalizadas e ficar secundarizadas no debate, além de quase sumirem na interface do site (MARTINS, 2006) ${ }^{11}$. Ou seja, também ali, num espaço típico da comunicação interativa em rede, um discurso prevalece sobre outro e impõe barreiras às contradições. Sendo assim, para se pensar o que representa esse novo autor em coletivo, múltiplo e transindividual, em termos de rarefação do discurso, é necessário fazer um esforço para fugir de análises apressadas e ter disposição de encarar a complexidade e o paradoxo da comunicação humana, presente em qualquer época e através de qualquer tipo de mediação.

\section{O declínio do especialista}

Uma última característica que vale a pena destacar, pois diz respeito ao caso Overmundo, é a relativização do renome do autor. Mesmo que o questionamento da natureza subjetiva da autoria tenha começado ainda no século XIX, a produção continuou referenciada

\footnotetext{
${ }^{9}$ De acordo com a administração da enciclopédia eletrônica colaborativa: "Na Wikipédia em português, página protegida é uma página com um mecanismo de restrições controlado pelos administradores, que se refere à edição ou a movimentação da página. Proteger uma página é uma medida extrema, reservada normalmente aos casos nos quais a discussão não surte mais efeito". Informação disponível em: <http://pt.wikipedia.org/wiki/ Wikipedia: Página_protegida〉. Acesso em: 14 abr. 2014.

${ }^{10}$ Nos referimos aqui às interações cognitivas que se dão não só nas chamadas redes sociais, como Facebook ou Google + , mas também através de inúmeros sites, blogs e fóruns de discussão nos quais há interlocução entre os participantes.

${ }^{11}$ Endossando esta análise, Johnson (2002) e Lampe \& Resnick (2004) afirmam que os fóruns do Slashdot tendem ao fechamento de opinião e ao consenso, respectivamente.
} 
ao nome do especialista ou do artista como fator de sua qualificação. Do ponto de vista da validação da obra, importava saber quem escreveu e sob quais credenciais, científicas ou artísticas, para legitimar determinada produção. Cabe pontuar que a construção do nome de um artista ou especialista não se dá de forma autônoma, mas está inserida em uma dinâmica social da qual participam instituições, como as companhias editoriais, os coletivos de artistas e o meio acadêmico, que por sua vez estabelecem os critérios de qualificação para se alcançar o status de autor digno de publicação.

No entanto, na atualidade, a produção no meio digital, feita de forma interativa, tem demandado novos modos de valoração, com a criação de diferentes sistemas de avaliação que transferem para um coletivo a tarefa de qualificar o que foi publicado. Nesse sentido, os processos autorais em rede estão ensejando o surgimento de um tipo de autoridade distribuída, com o objetivo de dar conta da qualificação do conteúdo dentro de uma lógica também interativa. Nesse contexto, a produção é avaliada pelo seu mérito - uma linha de comando perfeita em um código-fonte ou um artigo consistente na enciclopédia - para além de prérequisitos, o que, entre outras coisas, abre espaço para a expressão da diversidade.

Essas reflexões que acabamos de fazer são uma tentativa de compreender a configuração do que estamos chamando de modelo autoral peer-to-peer. A seguir, apresentaremos a publicação eletrônica Overmundo como um exemplo desse novo paradigma autoral.

\section{O CASO OVERMUNDO}

O Overmundo é um website que traz notícias sobre cultura brasileira, produzidas pelo próprio público participante. O projeto foi lançado em março de 2006 com uma clara linha editorial: "servir de canal de expressão, debate e distribuição para a produção cultural do Brasil e de comunidades de brasileiros espalhadas pelo mundo afora tornar-se visível em toda sua diversidade". Seu objetivo, portanto, é dar espaço para a divulgação das mais diversas manifestações culturais do país, que de modo geral não são destacadas pela cobertura jornalística da grande imprensa brasileira, mais voltada para a produção cultural concentrada na região Sudeste, onde estão localizadas as principais metrópoles do país, como Rio de Janeiro e São Paulo.

Para dar conta dessa meta, existe uma comunidade virtual em torno da publicação, que hoje chega a mais de 49 mil participantes registrados ${ }^{12}$. Sua interface é, como tantas outras

\footnotetext{
${ }^{12}$ Dados referentes a abril de 2014.
} 
redes sociais, desenvolvida para incentivar a interação. Cada matéria tem uma área destinada ao seu conteúdo propriamente dito, com texto, ilustrações e fotos; e outra, aos comentários dos demais participantes. Deste modo, gera-se um ambiente propício ao debate sobre as mais diferentes iniciativas culturais das mais diversas regiões do país. Por último, complementando o sistema, existem perfis que representam cada participante inscrito no projeto, com algumas informações pessoais, o registro de suas publicações e preferências no site, e ainda recursos para interação com os demais.

O seu modelo editorial é open publishing, isto é, qualquer pessoa, desde que se registre, fornecendo alguns dados pessoais, pode enviar matérias para uma das suas áreas: overblog (reportagens, entrevistas e críticas); banco de cultura (obras culturais); guia (lugares, atividades, comidas, festas e eventos regulares); e agenda (programas e eventos). A proposta foi a de construir um sistema editorial interativo, no qual o público participante pudesse não apenas produzir o conteúdo, mas também editá-lo de forma colaborativa, e ainda definir os destaques na sua página principal, através de voto.

O sistema de publicação sofreu alguns ajustes desde o lançamento do projeto a fim de se adaptar às ações do público participante ${ }^{13}$. No início havia um índice chamado karma que media a reputação de cada participante, de acordo com suas colaborações publicadas e participação no projeto. Quanto maior o karma mais peso teria o voto na hora de decidir que matérias seriam publicadas nas áreas mais visitadas do site. No entanto, isso acabou gerando problemas, pois incentivou a criação de "panelinhas" que venciam sempre as votações e, assim, deixavam o restante das contribuições publicadas em áreas sem relevância. Por causa disso, em abril de 2009, decidiu-se extinguir o índice e simplificar o processo editorial. Segundo a equipe que administra o projeto, o objetivo das mudanças foi garantir, e privilegiar, a fruição das contribuições e a interação criativa em torno delas.

Atualmente toda a colaboração, como são chamadas as matérias enviadas ao site, é publicada imediatamente ou, opcionalmente, pode ir para a fila de edição, onde permanece por 48 horas para receber sugestões e críticas. As mais votadas ficam em destaque na home page. Depois de publicadas, as colaborações podem receber comentários. Em algumas delas, podemos identificar o diálogo entre o texto principal e os comentários, através de argumentos e questionamentos, que acabam ampliando e enriquecendo o conteúdo original. Este é o caso, por exemplo, da matéria "O Autor Coletivo", publicada em 3 de dezembro de 2006 por

\footnotetext{
${ }^{13}$ Para mais informações sobre a evolução do sistema de publicação do Overmundo, conferir: <http://www.overmundo.com.br/blog/observatorio>.
} 
Ronaldo Lemos, um dos criadores do projeto Overmundo ${ }^{14}$, sobre as mudanças da autoria na era das redes de comunicação. O texto recebeu 34 comentários. Destacamos alguns deles para dar uma ideia do tipo de diálogo que se constrói nesses ambientes:

\begin{abstract}
“Algo interessante a se refletir no tema 'produção colaborativa' é que ele tem servido também como referência para uma nova forma de organização política para grupos de trabalho. Quem trabalha em autogestão, pode utilizar o mesmo conceito. Ou seja, ao invés de tomada de decisão baseada pura e simplesmente em reuniões onde tudo é decidido pelo voto, as decisões passam a ser tomadas principalmente por quem mais participa. Estamos adotando isso no Coletivo TARRAFA." $\underline{\text { Alê }}$ Barreto $\cdot$ Rio de Janeiro, RJ 6/12/2006 11:3
\end{abstract}

"Bernardo, essas questões começam a ficar gigantescas e problemáticas, pois envolvem interesses corporativos absurdos. Mas concordo que algumas coisas devem entrar em debate sim. Meu pai inventou uma máquina doida de engenharia e nunca ganhou um centavo por ela, por exemplo. Atualmente o que mais me preocupa são as patentes sobre animais e elementos isolados de DNA que algumas empresas detêm." Fernando Mafra . São Paulo, SP 6/12/2006 14:05

"Ronaldo, todas essas questões estão aí é o momento de debate é agora. A informação livre pode gerar uma revolução bem bacana não só nas mídias, mas principalmente na sociedade. Mas o Bernardo levantou uma bola importante, que não pode ser ignorada: a propriedade intelectual (seja ela artística ou científica) é fruto do trabalho e do investimento de alguém. Isso também não pode ser ignorado nesse debate." Ilhandarilha . Vitória, ES 7/12/2006 09:13

Como se vê, os comentários podem trazer outros ângulos e pontos de vista a respeito do tema em pauta, enriquecendo o texto inicial. Outro ponto que merece ser ressaltado é que se trata de um processo em aberto: a partir de publicada, uma matéria pode receber comentários indefinidamente, estando, portanto, sempre passível de complementação.

\title{
UM EXEMPLO DE AUTORIA P2P
}

Depois desta breve apresentação do modelo editorial do website, cabe verificar sua constituição como uma produção peer-to-peer ${ }^{15}$. Em primeiro lugar, observamos que o Overmundo atende a uma das principais características da produção P2P: a não exigência de credencial. Qualquer pessoa pode participar do projeto, e não é preciso apresentar título ou ter

\footnotetext{
${ }^{14}$ Endereço eletrônico em <http://www.overmundo.com.br/overblog/o-autor-coletivo>. Acesso em: 14 abr. 2014.

${ }^{15}$ As características da produção peer-to-peer podem ser conferidas em <http://p2pfoundation.net/Peer_Production>. Acesso em: 14 abr. 2014.
} 
alguma especialização para publicar. Outro ponto determinante é da validação pelo coletivo e a não existência de um controle hierárquico. As matérias são publicadas diretamente sem passar por nenhum tipo de aprovação editorial centralizada. Só depois é que receberão votos dos demais participantes e, dessa forma, poderão ganhar destaque na página principal. Neste caso, não há nem mesmo uma avaliação posterior, como é comum em projetos de autoria P2P, como a Wikipédia. Todas as colaborações enviadas são publicadas e, a princípio, permanecem no site.

Por outro lado, a fiscalização sobre a violação dos termos de uso do projeto também é $\mathrm{P} 2 \mathrm{P}$, isto é, feita pelo próprio coletivo. Existe um sistema de fiscalização distribuída, através do recurso do botão de alerta, para que qualquer participante possa denunciar irregularidades, como: matérias que não digam respeito à cultura brasileira; publicação de propaganda ou spam; violação de direitos autorais etc. As denúncias são posteriormente verificadas pela equipe administrativa do Overmundo que, se for o caso, retira a matéria do ar.

Além disso, há instrumentos para assegurar que as colaborações se constituam em um bem comum e impedir sua apropriação privada. Para isso, os conteúdos do projeto são licenciados por meio de uma licença Creative Commons "Atribuição - Não Comercial Compartilha Igual 3.0 Brasil (CC BY-NC-SA 3.0)". Em outras palavras, isso quer dizer que quem participa mantém a titularidade dos direitos autorais e do uso comercial de sua contribuição, mas autoriza sua cópia ou distribuição, assim como a criação de obras derivadas. Estas últimas devem ter uso não-comercial e manter o mesmo tipo de licença, além disso devem citar o nome do autor da obra original.

Em uma definição sucinta: "Peer-to-peer is a form of relationality between human beings whereby people can connect to each other without permission, and aggregate around the creation of common value" 16 (BAUWENS et al, 2012, p. 158). Como se vê, o Overmundo é um projeto P2P: com um sistema editorial aberto à participação de qualquer pessoa, disponibiliza um vasto repositório de matérias sobre as mais variadas expressões da cultura brasileira, que provavelmente não existiria senão dessa maneira. $\mathrm{O}$ formato peer-to-peer possibilita e incentiva a participação do produtor cultural do interior do país e também do cidadão comum que vivencia as manifestações culturais de sua região. Da mesma maneira, o morador da favela ou de áreas mais pobres das grandes cidades fica em posição de igualdade para publicar seus relatos.

\footnotetext{
${ }^{16}$ A tradução é nossa: "Peer-to-peer é uma forma de relação entre os seres humanos através da qual as pessoas podem se conectar umas às outras sem pedir permissão, e unir-se em prol da criação de valor comum".
} 
Desse modo, o projeto consegue atingir seu objetivo de dar visibilidade, senão a toda, certamente a grande parte da diversidade da cultura brasileira. Alguns títulos de matérias publicadas foram selecionados, com o nome das cidades onde residem seus autores, para demonstrar o que foi afirmado:

\begin{tabular}{|l|l|}
\hline Título da matéria & Cidade/Estado \\
\hline Artesãs buscam alternativas no pinhão e na palha & Ponta Grossa/PR \\
\hline Vai um lambadão aí? & Cuiabá/MT \\
\hline Africanas (ou: vamos fazer um filme?) & Vitória/ES \\
\hline Projeto Afro de Tuxaua faz mapeamento & Campinas/SP \\
\hline Vai no passinho do menor da Favela & São João do Meriti/RJ \\
\hline Conexões litero-amazônicas & Boa Vista/RR \\
\hline Em nome da arte do interior & Anastácio/MS \\
\hline III Semana do Folclore Serra da Mesa & Uruaçu/GO \\
\hline A força do Projeto Encantadores do Sertão! & São João do Piauí/PI \\
\hline Festa bonita no Bonito & Brasília/DF \\
\hline O povo gosta é do pagode & Belo Horizonte/MG \\
\hline A Cultura em Santa Catarina: O que está faltando? & Florianópolis/SC \\
\hline O Som da Periferia do Recife: Rock In Rio Doce & Recife/PE \\
\hline
\end{tabular}

Por último, cabe fazer uma observação: quando foi criado, em 2006, o Overmundo representou um importante espaço para que a diversidade da cultura brasileira pudesse se expressar e, por isso mesmo, contava com grande afluência de colaboradores. No momento em que este artigo é finalizado, em abril de 2014, o site continua no ar, mas é visível o enfraquecimento da comunidade em torno do projeto: poucas colaborações, quase sem voto, e ainda a presença de propagandas ou artigos totalmente fora de tópico. Talvez pela ascensão das redes sociais, a produção cultural das diversas regiões do País tenha encontrado outras formas de divulgação mais eficientes. De todo modo, sem dúvida, o site continua sendo uma importante referência como uma experiência de autoria peer-to-peer. Além disso, se constitui também em um bem comum, na forma de um rico repositório, acessível a todos, sobre as mais variadas manifestações da cultura nacional.

\section{CONSIDERAÇÕES FINAIS}

Sob o impacto das redes de comunicação, as práticas autorais na atualidade são cada vez mais caracterizadas por processos interativos distribuídos em rede. Grandes exemplos desse novo paradigma autoral, o sistema operacional Linux e a publicação Wikipédia, são também casos emblemáticos de produção peer-to-peer. Por isso, em nossa visão, explorar as transformações nas práticas autorais, suas especificidades e dinâmica, é também estratégico para os estudos sobre a emergência da economia P2P. 
Neste artigo buscamos apresentar uma reflexão sobre o tema da autoria trazendo alguns referenciais teóricos para pensar o estatuto deste conceito e sua nova configuração na era das redes. A breve descrição do caso Overmundo fornece alguns elementos para melhor compreensão desse novo modelo autoral e também serve como exemplo de um bem-sucedido caso brasileiro de produção peer-to-peer.

\section{REFERÊNCIAS}

ASCOTT, Roy. Art and Telematics: towards a network consciousness. In: GRUNDMANN, H. (Ed.). Art + Telecommunication. Vancouver: The Western Front, 1984, p. 25-67.

BAUWENS, Michel et al. Report: a synthetic overview of the collaborative economy. Orange Labs and P2P Foundation, 2012. Disponível em:

<http://p2p.coop/files/reports/collaborative-economy-2012.pdf>. Acesso em: 14 abr. 2013.

FOUCAULT, Michel. A ordem do discurso. 7. ed. Tradução Laura Fraga de Almeida Sampaio. São Paulo: Loyola, 2001.

O que é um autor?. 6. ed. Tradução António Fernando Cascais e Eduardo Cordeiro.

Lisboa: Passagens, 2006.

JOHNSON, Steven. Emergence: the connected lives of ants, brains, cities, and software. New York: Touchstone, 2002.

LAMPE, Cliff; RESNICK, Paul. Slash(dot) and burn: distributed moderation in a large online conversation space. 2004. Disponível em:

<http://presnick.people.si.umich.edu/papers/chi04/LampeResnick.pdf>. Acesso em: 01 mar. 2013.

MARTINS, Beatriz Cintra. Cooperação e controle na rede: um estudo de caso do website Slashdot.org. 2006. 115f. Dissertação de Mestrado. Escola de Comunicação, Universidade Federal do Rio de Janeiro, Rio de Janeiro.

SERELLE, Márcio. Redes anônimas: aspectos de dissolução do autor no ciberespaço. In: Interações midiáticas. PINTO, Julio; SERELLE, Márcio. (Org.). São Paulo: Autêntica, 2006, p. 61-75.

WEISSBERG, Jean-Louis. Entre produção e recepção: hipermediação, uma mutação dos saberes simbólicos. In: COCCO, Giuseppe; GALVÃO; Alexander Patez; SILVA, Gerardo (Org.). Capitalismo cognitivo: trabalho, rede e inovação. Tradução Eliana Aguiar. Rio de Janeiro: DP\&A, 2003, p. 109-131. 